\title{
¿México debe mirar a América Latina? Las posibilidades de la política exterior de México en la Comunidad de Estados Latinoamericanos y Caribeños
}

\author{
Paola Anahí Hernández Ozuna* \\ María Esther Morales Fajardo**
}

\section{RESUMEN}

Este documento identifica si existen posibilidades de la política exterior mexicana dentro de la Comunidad de Estados Latinoamericanos y Caribeños (Celac) para alcanzar una mayor proyección en la región. La política exterior se analiza desde una perspectiva procesal y se resaltan la contingencia histórica y las estructuras normativas e ideacionales de la Celac, como mecanismo de diálogo político al más alto nivel en la región. Se concluye que no existe una estrategia concreta por parte de la política exterior mexicana dentro de la Celac porque este espacio regional no ha representado una prioridad tangible y a corto plazo para el gobierno actual, pese a que México fue uno de los impulsores de su creación.

Palabras clave: México, Celac, política exterior, América Latina, espacio regional.

* Maestra en estudios en relaciones internacionales. Estudiante de doctorado, Universidad Nacional Autónoma de México - unam, (México) [paolanahihozuna29@gmail.com]

** Doctora en ciencias sociales con especialidad en relaciones internacionales. Investigadora titular, Centro Regional de Investigaciones Multidisciplinarias-Universidad Nacional Autónoma de México Crim-UnAM, (México) [moralesf@correo.crim.unam.mx]

Recibido: 25 de mayo de 2017 / Modificado: 8 de marzo de 2018 / Aceptado: 7 de junio de 2018

Para citar este artículo:

Hernández Osuna, P. A. y Morales Fajardo, M. E. (2018). ¿México debe mirar a América Latina? Las posibilidades de la política exterior de México en la Comunidad de Estados Latinoamericanos y Caribeños, OASIS, 28, pp. 151-170. DOI: https://doi.org/10.18601/16577558.n28.09 
Should Mexico look at Latin America? The possibilities of Mexico's foreign policy in the Community of Latin America and Caribbean States

\section{ABSTRACT}

This document identifies if there are possibilities for Mexican foreign policy within the Community of Latin-American and Caribbean States (Celac) to achieve a major regional projection. Foreign policy is analyzed from a procedural perspective and the historical contingency and normative and ideational structures of Celac are highlighted, as a mechanism of political dialogue at the highest level in the region. It is concluded there is no concrete strategy on behalf of Mexican foreign policy within Celac because this regional space has not represented a tangible and short-term priority for the current government, even though Mexico was one of the promoters of its creation.

Key words: Mexico, Celac, foreign policy, Latin America, regional space.

\section{INTRODUCCIÓN}

La política exterior mexicana enfrenta retos ante el nuevo gobierno de los Estados Unidos (EE.UU.) y una inminente transformación (o desaparición) de su principal acuerdo comercial (Tratado de Libre Comercio con América del Norte, TLCAN). Por lo que el acercamiento a América Latina, a través de la Celac, se con- vierte en una posibilidad para el contrapeso a la influencia estadounidense.

La Celac es un espacio informal y multilateral que busca el diálogo y la concertación política entre los gobiernos de América Latina y el Caribe (sumando 33 Estados). Se concibe como un foro que pretende la convergencia de posiciones que coadyuven a la resolución de conflictos, permita la construcción de una gobernanza regional eficaz y la proyección de una agenda regional basada en la interacción y aprovechamiento de los avances presentes en los procesos de integración existentes.

La informalidad de la Celac descansa en que no fue concebida como una organización internacional, ya que hasta el momento no se ha firmado un acuerdo vinculante entre sus partes (pacta sunt servanda). No es una organización internacional porque no posee una estructura institucional permanente que sea independiente de los gobiernos (Segovia, 2013). Ni tampoco posee una estructura organizada o un cuerpo burocrático, una sede y normas regulativas-prescriptivas que den forma a una estructura legal definida. Hasta ahora, la celebración anual de cumbres, la conformación de la secretaría pro tempore y la troi$k a$, así como las reuniones anuales o bianuales (temáticas) de ministros o representantes y los grupos de trabajo sectoriales son las formas de funcionamiento de este espacio.

Esta particular forma de funcionar la hemos relacionado con la diplomacia de cumbres y la existencia de un regionalismo ligero (Sanahuja, 2016) que se halla dentro de la cooperación y el multilateralismo latinoamericano (Legler, 2010). El multilateralismo ligero también se entiende bajo el concepto 
de regionalismo heterodoxo que plantea Van Klaveren, caracterizado por un pragmatismo y por la superposición de múltiples vías de acción que incluyen mecanismos formales e informales, procesos multilaterales o bilaterales, esquemas regionales o subregionales (Van Klaveren, 2012, p. 137).

La creación de un espacio de diálogo regional, sin la presencia de EE.uU. y Canadá, fue uno de los imperativos que dieron origen a la Celac (Rojas Aravena, 2011 y Llenderrozas, 2013). Para México, el surgimiento de la Celac representó la estrategia reactiva de reajuste y recomposición ante sus pares latinoamericanos, después de un alejamiento político y comercial a raíz de su adhesión al TLCAN, la vinculación histórica de sus relaciones internacionales con su vecino del norte y la escalada de conflictos diplomáticos con América Latina a partir del 2000.

Autores como González y Pellicer (2013) y Saltalamacchia (2011) mencionan que el motivo que impulsó la iniciativa mexicana para la creación de la Comunidad fue el intento de reforzar su presencia en Latinoamérica contrarrestando, con ello, su ausencia en otros mecanismos de cooperación política. Sanahuja (2017, p. 39) considera que la Celac

respondería a las pretensiones de México de diversificar su política exterior hacia América Latina y el Caribe y contar con un marco de interlocución regional, reafirmando su identidad latinoamericana, ya que [su vinculación comercial con Estados Unidos] y su política exterior [...] le ha situado en una posición relativamente alejada y excéntrica respecto a las dinámicas regionales.

Nos preguntamos entonces ¿cuáles son los verdaderos alcances de la política exterior mexicana con América Latina en el marco de la Celac? El objetivo de este documento es identificar si existen posibilidades de la política exterior mexicana dentro de la Celac para alcanzar una mayor proyección en la región.

El estatus de las relaciones con América Latina y la reconfiguración del continente, exigían a México un acercamiento menos discursivo con la región; por lo que la Celac se configura como ese espacio flexible (en cuanto no hay normas que restrinjan la actuación de los países y no solicitan una filiación ideológica específica ${ }^{1}$ ), en el cual los hacedores de política exterior y los tomadores de decisiones mexicanos pudieran establecer una estrategia global de acercamiento con la región, para incentivar la cooperación en aquellos sectores en donde ya existe y abrir una veta de diálogo con aquellos países distanciados.

El documento que se presenta es el resultado de una investigación documental y con un enfoque de análisis comprensivo para profundizar en el conocimiento de la política exterior mexicana en sus relaciones con América Latina y el Caribe, en el marco de un organismo como Celac.

El artículo contempla tres apartados, además de esta introducción. El primero

1 Lo que no compromete, en absoluto, el proyecto de nación de México y permite una convivencia armónica con los intereses creados y sostenidos con otros interlocutores como extrarregionales, no importando tampoco la naturaleza de estos. 
concerniente al marco analítico-procesal de la formulación de la política exterior. Además del constructivismo de las relaciones internacionales para el análisis de la contingencia histórica y las estructuras normativas e ideacionales (Wendt, 1999), en la conformación de la Celac, en cuanto a la idea de la identidad colectiva en las relaciones entre los Estados y al centrarse en la influencia de las ideas y normas en el comportamiento de estos actores.

La segunda sección aborda la naturaleza de la Celac, como un organismo de concertación y cooperación política regional analizada desde la contingencia histórica y de sus estructuras normativas e ideacionales, y la tercera analizará los cambios, transformaciones y adecuaciones de la política exterior mexicana dirigida hacia América Latina, así como las perspectivas de México en el seno de la Celac y sus verdaderos alcances en ella. Finalmente, en un apartado de conclusiones detallaremos cuáles son los desafíos observados para la política exterior de México.

\section{CONSTRUCCIÓN DE LA POLÍTICA EXTERIOR Y LAS ESTRUCTURAS NORMATIVAS E IDEACIONALES EN LAS RELACIONES INTERNACIONALES}

$\mathrm{El}$ análisis de las relaciones internacionales de México, sin duda, ha sido determinado por la vecindad y el peso geopolítico que implica su cercanía con los EE.UU. De ahí que los factores o estrategias que determinan su relación con otros países encuentren su fundamento en la formulación de la política exterior mexicana. Si se concibe como una elaboración procesal a la política exterior, entonces en este apartado pretendemos repasar brevemente las principales fases que sustentan dicho proceso, a fin de identificar las pautas seguidas por México en su vinculación con América Latina a través de la Celac.

La política exterior es el resultado de un proceso que lleva a cabo un Estado y que está en función de criterios contingentes y tradicionales $^{2}$. Si bien diferentes actores intervienen o participan en el proceso de formulación de la política exterior, solo el Estado puede ejecutarla "[...] ya que son los únicos actores que reúnen los dos requisitos necesarios para poder desarrollarla plenamente: capacidad jurídica reconocida internacionalmente y capacidad política plena, autónoma y eficaz" (Calduch, 1993, p. 1). Por lo tanto, nuestro interés de análisis principal son las acciones del Estado mexicano y no los diferentes actores que intervienen en el proceso de construcción de su política exterior.

La formulación de la política exterior conlleva distintas etapas. Tomassini (1991, p. 147) identifica 5 principales: "1) la definición del interés nacional y la construcción de la agenda internacional de un Estado; 2) la operacionalización de intereses (que se incluyen en la agenda y se enuncian); 3) el establecimiento de objetivos; 4) la identificación de cursos de acción; y, 5) la toma de decisiones

\footnotetext{
2 "Los criterios contingentes se refieren a las preferencias externas del gobierno en turno y a los problemas o inputs que recibe del exterior. Los criterios tradicionales se refieren a los pactos y prácticas escritas y no escritas que han modelado la política exterior de un país" (Lasagna, 1995, p. 390).
} 
(individual o personal; grupal -a través de asesores-e institucional -división del trabajo"-y podría agregarse la evaluación y/o corrección de la misma) (Merino, 2013).

Morgenthau (1948) y Velázquez (2007, pp. 20-40) consideran que el interés nacional es el leitmotiv de toda política exterior, su construcción es a largo plazo y se relaciona con nociones como la de supervivencia y seguridad del Estado. Este interés se vincula con el proyecto de nación, que funge como la hoja de ruta que le permitirá a un país clarificar sus intereses.

El establecimiento de objetivos de política exterior debe concordar con el interés nacional y, además, servir de guía para la acción, como referentes particulares para alcanzar determinados resultados que son definidos como deseables, o bien, para minimizar o eliminar aquellos escenarios que son concebidos como adversos o no deseables (Herrera, 2011). La identificación de los cursos de acción se vincula con las capacidades - materiales e inmateriales-que tiene un país para desplegar y ejecutar una política exterior. Pueden ser mecanismos institucionalizados (canales diplomáticos, participación en organismos internacionales, cumbres presidenciales, firma de tratados internacionales), materiales (capacidad militar, tecnológica y/o económica) e inmateriales (prestigio, legitimidad política, industrias culturales, turismo, etc.).
Asimismo, los factores que intervienen en la formulación de la política exterior son tangibles u objetivos e intangibles o subjetivos, exógenos y endógenos ${ }^{3}$. De este modo, los factores de situación se combinan para construir, transformar o cambiar la dirección de la política exterior de un Estado.

La toma de decisiones es una de las etapas más importantes y complejas en el proceso de construcción de una política exterior, ya que a partir de toda la información que se recibe del exterior e interior, se establecen las acciones pertinentes (y realistas) para el cumplimiento del proyecto e interés nacional, así como de los objetivos planteados en los momentos iniciales de la formulación de esta política. En esta etapa tienen cabida criterios contingentes, preferencias externas, criterios tradicionales, prácticas políticas, así como percepciones, ideales y valores del grupo en el poder que mantienen o modifican la identidad internacional de un Estado. Por todo lo anterior, la política exterior no debe comprenderse como un bloque puro de hechos tangibles, ya que las fuerzas del pasado y las del presente pueden entrar en conflicto, coexistir e incluso sintetizarse.

La confluencia multinivel del proceso de toma de decisiones considera las fuentes de los inputs que provocan la adopción de ciertas decisiones. Al respecto de los inputs y outputs, Rosenau (en Singer, 1973) identificó la existencia de interacciones e interdepen-

\footnotetext{
3 Rosenau identifica una forma de "clasificar todas las fuerzas potenciales que influencian la política exterior de una nación en cinco grandes categorías: el contexto internacional, el contexto social de la nación, el gobierno, el rol de los hacedores de política exterior, y las características individuales de las élites hacedoras de política exterior” (en Kegley \& Wittkopf, 1991, p. 12) Traducción libre.
} 
dencias entre elementos que confluyen en el planteamiento de estrategias y en la toma de decisiones de quien se encarga de formular y ejecutar la política exterior.

A este respecto, la teoría del linkage establece que a) el linkage es una secuencia recurrente de comportamiento que es causa o consecuencia de otro, no es un fenómeno aislado; b) que debe tratar de eliminarse, para un análisis, la frontera entre política interna y política internacional, para entenderse como dos sistemas en constante interacción, interpenetración e interdependencia; c) que existen inputs y outputs que inician o terminan con el linkage y, finalmente, d) que existen tres tipos de linkage: penetrativo ${ }^{4}$, reactivo y emulativo ${ }^{5}$ (Del Arenal, 2007, p. 306).

En particular nos interesa el linkage reactivo y, también, el concepto de adaptative behavior porque consideramos que ese fue el actuar de la política exterior mexicana frente a la creación de Celac. El linkage reactivo se produce cuando los acontecimientos en un sistema político provocan una reacción en otro sistema político, sin que exista una participación directa de los miembros de un sistema en otro (Rosenau en Singer, 1973, p. 69).

En tanto que el adaptative behavior se refiere a que toda política exterior puesta en práctica por un gobierno se ha de concebir como adaptativa cuando provoca cambios en el entorno externo, que contribuye a asegurar las estructuras básicas de la sociedad dentro de los límites aceptables ${ }^{6}$. Desde la perspectiva adaptativa, todas las naciones pueden ser consideradas como entidades adaptables con problemas similares que surgen de la necesidad de enfrentarse a su entorno.

Para entender la actuación de México en su vinculación con los países latinoamericanos dentro de la Celac, es necesario remarcar la construcción de esta como un espacio de concertación política y de reivindicación de la identidad latinoamericana que, entre otras cosas, busca la autonomía y la unidad de los países de la región (Sanahuja, 2017; Valencia, 2015). Consideramos que algunas aportaciones del constructivismo, como enfoque analítico de las relaciones internacionales, contribuyen justamente a entender la idea de la identidad colectiva en las relaciones entre los Estados, al concentrarse en la influencia de las ideas y normas en el comportamiento de estos actores, en particular la utilidad que aportan los conceptos de contingencia histórica y estructuras normativas e ideacionales. Nos alejamos de la perspectiva del regionalismo latinoamericano y de la integración regional, no porque descartemos su utilidad analítica, sino porque la idea del documento radica en

4 Tiene lugar cuando los miembros de una unidad actúan en el proceso de otra unidad. Abarca no solo la penetración política y militar, sino también la económica (Del Arenal, 2007, p. 307).

5 Ocurre cuando la reacción que se produce en un sistema, a consecuencia de los acontecimientos que tienen lugar en otro es del mismo tipo que la acción que lo provoca (Rosenau, en Singer 1973, p. 69).

6 También existe la variante no adaptativa. Esta contribuye a que se produzcan cambios en las estructuras básicas más allá de los límites aceptables (Del Arenal, 2007, p. 307). 
el análisis de la política exterior de un país dentro de un foro o espacio de concertación política regional.

La contingencia histórica se refiere al contexto que está compuesto por ciertos niveles de desarrollo material y subjetivo que se basan en la manera de ver, entender y proyectar la sociedad en la que se vive. En ella, observamos la interacción e interpenetración de valores, historia, patrones de comportamiento, con los elementos del contexto que surgen a la luz de los acontecimientos del presente y de los resultados que tiene la implementación de ciertas decisiones basadas en las visiones del mundo.

Wendt (1999) arguye que el contexto o las contingencias históricas dentro de las que se desenvuelven los Estados serán edificados a través de las actuaciones de estos y, a la vez, estas actuaciones estarán guiadas por las interpretaciones intersubjetivas de la realidad.

Las estructuras normativas e ideacionales son códigos válidos para miembros de una sociedad o sistema (sea nacional, regional o internacional). Las estructuras son aquellas construcciones sociales dentro de las cuales actúan los individuos y/o los Estados que condicionan los puntos de vista de la sociedad, y las maneras en las que se desenvuelven en un sistema de mayor envergadura, como el internacional.

La estructuras normativas e ideacionales ${ }^{7}$ se observan ligadas a la concepción de contingencia histórica, lo que les otorga dos cualida- des: por un lado, la de ser altamente cambiantes y, por otro, la de contribuir a minimizar la incertidumbre de un actor, al permitirle formar una base estable de actuación conformada por una identidad y unos intereses específicos. Las normas son constitutivas porque le dan una razón de ser al agente que las interioriza y las hace suyas; y regulativas porque prescriben y proscriben ciertas conductas o prácticas que se contraponen al funcionamiento mismo de la estructura (Santa Cruz, 2009, p. 17). "Las estructuras normativas e ideológicas [...] son pautas de conducta social [pero también] condicionan y limitan las estrategias y acciones emprendidas por los Estados en la búsqueda de sus intereses" (Porcelli, 2013, p. 63).

Una vez establecidos y definidos los conceptos, daremos paso al apartado número dos que establecerá la naturaleza de la Celac para comprender sus verdaderos alcances y limitantes. Consideramos que, de esa manera, se podrá comprender la participación de México en esta, así como su estrategia en caso de que exista.

\section{¿QUÉ ES LA CELAC Y A QUÉ SE ENFRENTA EN UNA AMÉRICA LATINA CAMBIANTE E INCIERTA?}

La Celac se ideó como un espacio de diálogo intergubernamental que incluyera en su seno a los 33 países que conforman a América Latina y el Caribe. Su principal característica es su ca-

\footnotetext{
Wendt asegura que "las estructuras están determinadas por ideas compartidas más que por fuerzas materiales; y que las identidades y los intereses están constituidos por esas ideas compartidas en lugar de estar dados de manera material" (en Vitelli, 2014).
} 
rácter informal, flexible y multilateral que no pretende convertirse en un ente supranacional, fuente de acuerdos jurídicos vinculantes, ni un mecanismo formal de integración. Como asociación de Estados, la Comunidad persigue un solo fin: la concertación multilateral para la creación de una agenda latinoamericana (Ayllon y Emmerich, 2015; Cardoso, 2013; Sanahuja, 2017; Segovia, 2013; Valencia, 2015).

El carácter informal y flexible de la Celac descansa en el hecho de que no es un sujeto formal del derecho internacional, porque no se ha constituido como una Organización Intergubernamental (OIG) ${ }^{8} \mathrm{y}$, además, porque no existe un tratado internacional que le dé vida, en consecuencia, los acuerdos no tendrán un carácter vinculante (pacta sunt servanda $a^{9}$ ).

De esta forma, se observa la inexistencia de normas (codificadas) que restrinjan la actuación de los países y, sobre todo, no existe el requisito de filiación ideológica, por lo que confluyen en su seno regímenes políticos de cualquier naturaleza, respetando su lema "unidad en la diversidad", aunque la Celac ha dejado claro que la democracia es un bien regional que debe observarse y ejercerse ${ }^{10}$. Justo esta cualidad la hace un espacio ideal para la concertación por encima de diferencias ideológicas o económicas, tejiendo redes de negociación face to face para destrabar o impulsar negociaciones estancadas.

La propuesta formal para la creación de la Comunidad se dio durante la Cumbre de la Unidad del Grupo de Río ${ }^{11}$ (GR) en 2010, presidida en ese momento por México. En la génesis de la Celac, la herencia normativa del GR fue trascendente por lo que había logrado en el "ámbito de coordinación y consulta política, con un significativo impacto en la prevención y superación de algunos conflictos, tanto intra como interestatales en la región" (Hershberg et al., 2014, p. 14), así como las metas estratégicas de la inclusión geográfica ampliada al no condicionar la pertenencia ni la inclusión por cuestiones políticas o ideológicas.

En su objetivo de proyectar a la Comunidad como un ente unificado hacia el exterior, se han establecido foros de diálogo con actores

8 Una organización internacional es "una asociación de Estados, establecida por un acuerdo entre sus miembros y dotada de un aparato permanente de órganos, encargados de perseguir la realización de objetivos de interés común por medio de una cooperación entre ellos [...] las oIG nacen a la vida internacional mediante la firma y ratificación de un tratado internacional por parte de los estados fundadores, que de ese modo establecen una regulación jurídica internacional, en la que se especifican los objetivos, estructura, funciones y medios, composición y membrecía, medios de participación y votación [...] Estos tratados internacionales constitutivos o fundacionales son, al igual que otro tratado internacional, normas de derecho internacional que obligan a los Estados signatarios entre sí y frente a terceros países" (Calduch, 1993, pp. 1-3, 8).

9 “[... prescribe la obligatoriedad de los pactos. Este principio puede equipararse al enunciado del derecho interno de que los pactos legalmente celebrados deben ser puntualmente cumplidos” (Méndez, 1970, p. 93).

10 "A través de la "Declaración Especial sobre la Defensa de la Democracia” de 2011, la Celac [...] cuenta con un procedimiento y opciones en esta materia que van desde la mediación hasta las sanciones” (Sanahuja, 2016, p. 51).

11 Celebraba de manera conjunta la Cumbre del GR y de la tercera Cumbre sobre Integración y Desarrollo (Calc). Se llevó a cabo en Cancún, México. 
extrarregionales. "[...] la Celac ha sido designada de manera expresa como la interlocutora regional ante la UE, y a través de su presidencia y de la troika inició en 2012 un diálogo político regular con actores estratégicos como India, China, Corea del Sur, Turquía, Japón, el Consejo de Cooperación del Golfo, y la Federación Rusa" (Sanahuja, 2016, p. 51).

La continuidad de los temas e iniciativas para la conformación de una agenda y la proyección regional está debilitada debido a la rotación anual de la Presidencia Pro Tempore (PPT); por otro lado, la falta de un compromiso institucionalizado y vinculante, que obligue a los países a llegar a acuerdos concretos y a cumplir metas en un lapso de tiempo determinado, es otro factor que resalta la ausencia de un seguimiento a las agendas que se construyen en las cumbres anuales ${ }^{12}$.

\section{La contingencia histórica en el nacimiento de la Celac}

La Celac es producto de una contingencia histórica o de una situación contingente porque ha obedecido a un contexto particular y cuenta con características que lo singularizan. En la Celac, los cambios en el contexto regional han marcado su curso de acción.

La Celac se creó sin saberlo, en los estertores de la ola progresista y de izquierda que llegó a América Latina en los albores del siglo xxi. Fue en este tiempo, que se creyó que la creación de una organización informal era necesaria frente al papel inclinado hacia los intereses norteamericanos que había tenido la Organización de los Estados Americanos (OEA) desde su nacimiento (De la Barra y Dello Buono, 2012; Valencia, 2015). La búsqueda de la autonomía (Valencia, 2015) en la toma de decisiones fue la base que se pensó para la proyección de los países latinoamericanos y los mecanismos de diálogo y concertación intra y extrarregionales.

La primera década del siglo xxi representa una etapa importante para el desarrollo de la política regional e internacional debido a la expansión de los países emergentes, como China, que anclaron paradigmáticamente su crecimiento en las exportaciones de commodities latinoamericanos. Lo anterior tuvo como respuesta un mayor impulso de la autonomía en la toma de decisiones y la reconfiguración del mapa político latinoamericano (Bonilla y Álvarez, 2013, p. 383). El impulso también estaba dirigido a señalar que en los foros multilaterales de carácter universal había una crisis de desprestigio y legitimidad que aumentaba las dudas acerca de sus verdaderas capacidades para velar por la paz y la seguridad internacionales, en el sistema internacional del siglo XXI.

En este sentido, Ruggie hace una pertinente distinción entre las instituciones multilaterales y la institución del multilateralismo, en donde las primeras son la expresión de un multilateralismo formal y juridicista, y la se-

\footnotetext{
12 Hasta ahora se han llevado a cabo 6 cumbres presidenciales y las reuniones correspondientes de 30 sectores que confluyen en su seno alrededor de 21 ejes temáticos que han centrado sus actividades en la definición de agendas de discusión en políticas y programas concretos (Sanahuja, 2016, p. 51).
} 
gunda hace referencia a un multilateralismo activo y sustantivo en donde la coordinación es con base en códigos o principios de conducta que son legitimados, generalizados e interiorizados (en Costa Fernández, 2013, p. 10).

En América Latina notamos que la institución del multilateralismo está nutrida por la informalidad de los espacios de concertación, sobre todo en materia política (tenemos el ejemplo del Grupo de Contadora, el GR y, obviamente, la Celac), que descansan en la voluntad política de los Estados. Aunque estas estructuras normativas no tienen un carácter prescriptivo legalmente hablando, sí poseen un carácter sustantivo que establecen pautas de conducta que regulan las relaciones que se dan entre los Estados, que las sancionan por medio del consenso (o no) y del reconocimiento (o no).

La ola latinoamericanista de inicios del siglo XXI logró consolidar ciertas características particulares para la cooperación y darle un nuevo sentido a la integración regional latinoamericana, no solo por el surgimiento de Celac, sino por el conjunto de esquemas que se alejaban de la noción del libre comercio hasta el momento imperantes, tales como la Unión de Naciones Sudamericanas (Unasur) o la Alianza Bolivariana para los Pueblos de Nuestra América (Alba). De ese modo, observamos que la contingencia histórica en donde nació la Celac, conformó una gama de conductas, ideales y normas (tácitas) en las cuales se desenvolvieron las políticas exteriores de los Estados que participaron en la construcción de la concertación política latinoamericana.

Sin embargo, en la avanzada segunda mitad del siglo xxi "El giro hacia la derecha en la región, es una tendencia que parece haberse iniciado con los cambios de gobierno en Argentina, Brasil o Perú, tiene como objetivo declarado "volver al mundo" y reinsertarse en las dinámicas de la globalización, a través del libre comercio" (Sanahuja, 2016, p. 53). Este giro forma parte de la historia de la Celac y no de su contingencia inicial.

Las características del ambiente político y económico en América Latina de los últimos dos años (2016-2017) distan mucho de aquellas que vieron en 2010 el nacimiento de la Comunidad. Actualmente, las incertidumbres electorales, los problemas económicos y el viraje, en la mayoría de los países latinoamericanos, hacia la derecha y la profundización de los lazos comerciales y la globalización neoliberal, a través de la formación de zonas de libre comercio a gran escala, han mermado la visibilización y el impulso de la Celac aunque, hasta el momento, sigue funcionando sin mayores obstáculos.

\section{La formación y el funcionamiento de las estructuras normativas e ideacionales en la Celac}

En los procesos de cooperación y concertación política entre los países latinoamericanos se han formado estructuras normativas e ideacionales en las que confluyen los principios del derecho internacional e ideales (igualdad, respeto y solidaridad) que dan origen a normas de conducta tácitas que, se espera, sean observadas. Esos códigos de conducta generan también ciertas pautas de comportamiento que caracterizan los esfuerzos de diálogo, concertación y/o cooperación en una región específica. 
En el caso de América Latina, resalta la existencia de un multilateralismo latinoamericano (Legler, 2010) expresado en un regionalismo ligero y disperso ${ }^{13}$ que tiene, como fines principales, la coordinación y el diálogo político. La defensa de la soberanía estatal clásica, la territorialidad, el intergubernamentalismo y la celebración de cumbres presidenciales han arraigado tanto a la región, que han sido las normas constitutivas (construidas a partir de estructuras ideacionales) que permiten dotar de una identidad singular (de actuación, de legitimación, subjetivación e intersubjetivación) a la forma y calidad de las relaciones entre los Estados latinoamericanos.

Van Klaveren (2012) ha preferido llamarlo regionalismo heterodoxo, arguyendo que se trata de un nuevo escenario de la cooperación caracterizado por un mayor pragmatismo comparado con las experiencias anteriores de integración y por la superposición de múltiples vías de acción, que incluyen mecanismos formales e informales, procesos multilaterales o bilaterales, esquemas regionales o subregionales, acciones amplias o restringidas.

De esta forma, la combinación de estas estructuras normativas con las estructuras ideacionales (que descansan en la solidaridad, flexibilidad, pluralidad, gradualidad, la complementariedad de acciones, la unanimidad en las decisiones y/o la participación voluntaria en iniciativas) le dan a la Celac sus principales características. Esas características específicas se reflejan en las cinco cumbres presidenciales, declaraciones oficiales y planes de acción que desde 2013 han reunido a los integrantes. Las estructuras ideacionales también se reflejan en la necesidad de construir ese mecanismo de concertación política, la búsqueda del consenso, el unionismo y la identidad latinoamericana (Sanahuja, 2017); así como la proyección de un espacio de interlocución con otros bloques o países extraterritoriales (Ayuso, 2015), un espacio para el debate, la coordinación y la articulación de temas prioritarios para la región, Ayllón y Emmerich (2015) y la aspiración a ser la cúspide de los procesos de integración latinoamericanos para llegar a la unidad y la autonomía de la región (Valencia, 2015).

Sin embargo, la base de esas estructuras ideacionales también son una fuente de debilidad. En un inicio, la Celac fue vista como un proyecto antagónico para afrontar la acción de EE.UU. y la agenda de la oeA en la región. Con el giro hacia la derecha en algunos países, este mecanismo está inmerso en visiones encontradas (Ayuso, 2015). Segovia (2013) resalta que debido a su flexibilidad institucional, la Celac posee una limitada influencia por la diversidad de sus miembros y la incapacidad de identificar intereses mutuos entre sus participantes, además del riesgo de que los países que la presiden puedan utilizarla como un foro para ventilar sus propios intereses políticos.

Lo cierto es que esta combinación de estructuras hace que la Celac se alce como el punto de encuentro al más alto nivel en

\footnotetext{
13 "Sometido a crecientes fuerzas centrífugas derivadas de la proliferación de negociaciones y compromisos comerciales multilaterales, plurilaterales y bilaterales" (Sanahuja, 2016, p. 39).
} 
América Latina y el Caribe, porque es el único foro que convoca a los jefes de Estado y de gobierno de toda la región, sin la presencia de los EE.uU. y Canadá.

\section{LA POLÍTICA EXTERIOR DE MÉXICO EN EL SENO DE LA CELAC}

La política exterior no solo debe abstraerse a la ejecución de una acción o a la obtención de un resultado, sino que detrás de los fines y objetivos concretos que se persiguen, se observa la existencia de otras etapas igual de importantes al momento de tomar una decisión y ejecutar una política exterior. La etapa de la conformación de intereses es fundamental ${ }^{14}$.

Los cambios que se suceden en el sistema internacional afectan la formulación y ejecución de la política exterior, pero también el cambio de tipo de régimen o de sistema político ${ }^{15}$ provocará una transformación, reconstrucción, reconfiguración, ajuste o modificación en la dirección de la política exterior de Estado. Sin embargo, los cambios radicales se dan a menudo en un contexto de crisis o transición que incluye una modificación (a veces gradual y otras no) de todos y cada uno de los valores de situación.

México es un país que enfrenta un escenario complejo debido a su condición emergente y la naturaleza de su vecindad geográfica que condicionan, en gran medida, sus estrategias de política exterior. De la misma forma, la construcción de sus valores históricos y el desarrollo de los sucesos en el ámbito internacional afectan la planeación y la dirección de su política exterior (Lafer, 2000).

Los vertiginosos cambios en el entorno interno e internacional en los años 80 del siglo xx modificaron los objetivos y estrategias de la política exterior mexicana, así como la esencia de su proyecto de nación e interés nacional. La complejidad del nuevo contexto obligaba a la política exterior mexicana a buscar la legitimidad y validez de sus principios tradicionales ${ }^{16}$ y su capacidad de adaptación a las nuevas coyunturas internacionales y regionales que se presentaban.

González (2001, p. 620), observa que en la década de los ochenta del siglo $\mathrm{xx}$, la po-

14 En relación con los intereses Rafael Velázquez señala que son "los fundamentos de la política exterior y provienen de dos fuentes: unos están basados en elementos vitales y funcionales, como la habilidad de la sociedad para subsistir, [...] la defensa [y los] otros están cimentados en valores nutridos por la sociedad [como] las preferencias, creencias, [la existencia] de un pasado [compartido y particular]" (Velázquez, 2007, pp. 29-24).

15 "Los efectos del tipo de régimen y el cambio de régimen dentro y entre las naciones acrecentará significativamente la capacidad interpretativa de cualquier enfoque que se proponga explicar las modificaciones del comportamiento de la política exterior [...] Los objetivos de los líderes de los regímenes asignan a la política exterior las limitaciones [al igual que] el sistema político interno” (Muñoz, 1987, p. 428).

16 El artículo 89, fracción X de la Constitución Política de México refiere los principios: la autodeterminación de los pueblos; la no intervención; la solución pacífica de controversias; la proscripción de la amenaza o el uso de la fuerza en las relaciones internacionales; la igualdad jurídica de los Estados; la cooperación internacional para el desarrollo; el respeto, la protección y promoción de los derechos humanos y la lucha por la paz y la seguridad internacionales (Constitución Política, 2017). 
lítica exterior mexicana transitó "[...] desde una postura ideológica y juridicista hacia el pragmatismo, un alineamiento con los Estados Unidos y un patrón de compromiso selectivo con instituciones internacionales". La crisis multidimensional al interior y al exterior obligaba a los tomadores de decisiones en materia de política exterior a una reingeniería de los intereses y objetivos que se perseguirían, optando al final por una integración silenciosa con EE.UU. ${ }^{17}$ El nuevo proyecto de nación e interés nacional se definía en términos de profundización de la economía neoliberal, de apertura de la economía mexicana a las fuerzas del mercado y de desplazamiento de las funciones clásicas del Estado, así como de defensa de la democracia y los derechos humanos. Esta nueva identidad quebró ciertos acuerdos tácitos (indiferencia benévola) entre México y algunos países de América Latina, que tuvieron mayor proyección en los casos de Cuba y Venezuela.

La coyuntura política que atravesó el país en el 2000, con la llegada al poder de un presidente de diferente espectro político al que había gobernado el país durante 70 años, no hizo más que reafirmar la alineación políticacomercial con los EE.UU. y ampliar la brecha política de alejamiento con América Latina, con el enfrentamiento diplomático con países como Cuba, Venezuela, Chile y Argentina. La formulación de la política exterior mexicana careció de un proyecto a largo plazo, sin una estrategia definida hacia América Latina y más reactiva que propositiva en cuanto a los intereses en la región.
Por ello, es que a partir del 2007 y con el arribo de un nuevo gobierno, se intentó limar las asperezas con los países de la región e intentar un nuevo acercamiento. Los trabajos anteriores a la creación de la Celac, desde la presidencia pro tempore del GR, abrieron esa posibilidad de reconciliación con la región. Valencia (2015) señala que fue loable la acción diplomática de México para colocar los cimientos de la Celac a través de la Reunión de Altos Funcionario (RAF) para los preparativos de la Cumbre de América Latina y el Caribe (Calc) y la xxvir Reunión de Ministros de Relaciones Exteriores, ambas realizadas en la ciudad de Zacatecas, México, en el 2009. El país también fungió como anfitrión de la I Cumbre de la Calc en 2010 y desde su posición como en el GR enfatizó en la idea de un mecanismo original para convergir los intereses del GR y de la Calc para dinamizar el diálogo político en la región (Valencia, 2015).

Por lo tanto, el 2010 parecía el año que cambiaría la política exterior dirigida hacia América Latina. México decidió adherirse al impulso de crear un nuevo espacio latinoamericano para reiterar la identidad y revivir el regionalismo latinoamericano (Soriano, 2012), pero sin avizorar cuáles serían las estrategias y los beneficios a largo plazo. En ese contexto, la estrategia mexicana tuvo dificultades debido a la visible fragmentación regional, al reacomodo de algunos mecanismos de integración ante los contradictorios resultados de un regionalismo abierto y a la existencia de gobiernos de izquierda, en la mayoría de los

17 Que institucionalmente comenzó con la firma del TLCAN. 
países sudamericanos, con agendas revisionistas frente al orden internacional y la posición mexicana de mantenimiento del statu quo (adaptative behavior).

Sin duda, por la estructura de la política exterior mexicana, que está concentrada en la liberalización de la economía y la creciente integración con América del Norte, tenía un camino difícil para insertarse cómodamente en esta nueva corriente de pensamiento en América Latina.

Con la participación de México en la creación de la Celac, el gobierno tenía la oportunidad de concretar una estrategia para adaptarse a las nuevas tendencias de cooperación regional, aunque jamás se evidenció un viraje ideológico por parte de la política exterior mexicana, ni un compromiso más allá de los límites aceptables por su estrategia de inserción internacional. Por lo tanto, creemos que actuó en concordancia con lo que Rosenau llama adaptative behavior: participar en los cambios que un espacio como la Celac pudiera provocar a largo plazo, pero siempre dentro de los límites aceptables de la estructura del sistema internacional, buscando reforzar sus pilares básicos.

No obstante, su interacción con la región y el interés de acercarse a lo que estaba pasando en América Latina actuaron como un linkage reactivo que provocó que México impulsara la génesis de la Celac. De esa forma, la Comunidad se pensó como la herramienta que -teóricamente- podría incrementar la presencia política mexicana en los debates y toma de decisiones regionales de los que estaba excluido (Saltalamacchia, 2011; González y Pellicer, 2013). El ejercicio y participación en el diálogo político, la coordinación y concertación de opiniones servirían a dos de los objetivos tradicionales de la política exterior mexicana: acercarse a Latinoamérica y contribuir al fortalecimiento del proceso de integración regional multidimensional.

A pesar de lo anterior, la continuidad en este impulso se perdió con el inicio del gobierno de Enrique Peña Nieto en el 2012, al no conocerse -hasta el momento- estrategias concretas de acción, objetivos a largo plazo ni un anclaje visible de los intereses y objetivos de política exterior mexicana con las funciones que se desarrollan en el seno de la Celac. La muestra más clara de la escasa importancia que le dio este gobierno al mecanismo fue la ausencia del presidente en las cumbres presidenciales de 2015 y 2017 (Franzoni, 2017). Varios factores explican el constante rezago de la Comunidad en el horizonte de la política exterior mexicana: 1) el intensivo y expansivo debilitamiento del contexto interno, que ha provocado la concentración de los recursos en revertir los niveles de violencia en el país. 2) La concentración en su relación con EE.UU. y la incertidumbre política y económica que genera la posible conclusión definitiva del tLCan. 3) Su preferencia por la creación de espacios minilaterales de cooperación económica, como la Alianza del Pacífico (AP). 4) La insuficiente capacidad de negociación internacional provocada por un contexto interno hostil y un contexto externo (sobre todo en EE.UU., su principal interlocutor) adverso que debilita en gran manera la proyección de México. 5) Y la propia perspectiva que adoptó la cancillería mexicana respecto a Celac, que como apunta Franzoni (2017), la vislumbró incapaz de reunir los consensos necesarios en la región. 
En el Plan Nacional de Desarrollo 20122018, se observa una importante debilidad estratégica para perseguir objetivos concretos al interior de la Comunidad, ya que en ninguna parte del documento se menciona cuáles serán los esfuerzos que se realizarán para acercarse a América Latina en bloque (complementando los lazos bilaterales con los que ya cuenta). Las actuales estrategias de acercamiento de la política exterior mexicana siguen transitando por el sendero de la economía y el intercambio comercial, sin observarse un despliegue de herramientas concretas que permitan la cooperación y el diálogo político.

Hasta el momento, la proyección internacional y regional de México tendría que basarse en las estrategias de acercamiento político a través del diálogo regional; la creación de plataformas de liderazgos múltiples (en donde la Celac jugaría un papel especial); el acercamiento económico y la posibilidad de construir una posición común en organismos multilaterales. No obstante, el gobierno mexicano, a través del presidente y la Secretaría de Relaciones Exteriores, ha condenado a la Celac a ser un foro meramente protocolario que parece haber rebasado el impulso que se le dio en el sexenio calderonista.

Si, en lo que concierne a América Latina, la política exterior de México aspira a que el país sea un puente efectivo y legítimo entre la dicotómica idea de un Norte y un $\operatorname{Sur}^{18}$, es necesaria la construcción e implementación de un diálogo político regional satisfactorio en el seno de espacios multilaterales como Celac, en donde las alianzas o acuerdos a los que lleguen los países se realicen sin un mandato específico, pero en donde exista -como telón de fondo- una infraestructura jurídica que ya se ha trabajado en otros mecanismos de integración.

Hoy más que nunca, la política exterior mexicana requiere un contrapeso ante los desafíos que presenta su relación con los EE.UU. y necesita aliados históricos que proyecten un respaldo solidario a nivel hemisférico. América Latina, entonces, se alza como uno de los eslabones que haría frente a los desafíos del poderoso vecino mexicano, sumado a una efectiva estrategia de diversificación y contrapesos.

En la coyuntura que se presenta en el 2017 con la complejización de sus relaciones con EE.UU. -debido al impulso nacionalista y xenófobo que imprime la presidencia de Donald Trump-, la Celac debería ser un foro importante en el cual México sopese las oportunidades de cooperación estrecha con América Latina y explote la solidaridad política, pero no basada en una retórica simplista sino en un mecanismo de países likeminded ${ }^{19}$ o de asociaciones selectivas.

La conformación de la Celac con una estrategia definida era un instrumento para reencauzar la relación de México con la re-

\footnotetext{
18 Posición compartida por Green (Camhaji y Valenzuela, 2015), Schiavon et al. (2006), Saltalamacchia (2011) y González y Pellicer (2013).

19 “[...] países con los cuales hay afinidades en materia de políticas públicas y una considerable sintonía internacional" (Van Klaveren, 2012, p. 148).
} 
gión, un retorno a los asuntos regionales ( $\mathrm{Sa}$ nahuja, 2017), la oportunidad para superar el aislacionismo con Suramérica y acercarse con los países que habían tenido menos tensiones (Manaut, 2016) y, al mismo tiempo, consolidarlo como un actor con responsabilidad global $^{20}$ por varias razones. Primero, porque expresaría un deseo de inmiscuirse en la resolución de desafíos de la región. Segundo, porque esto le permitiría participar más de cerca en la construcción de una estabilidad regional y consolidaría su imagen en la sociedad internacional. Tercero, porque este compromiso regional también sería un puente ideal para la promoción de los intereses nacionales que se muestran más apremiantes para el gobierno (como la seguridad, el desarrollo y la gobernabilidad democrática); y para el cumplimiento de objetivos de política exterior (como el reforzar las posiciones que se enarbolan en el seno de otras instancias multilaterales de las que México es parte y no puede actuar solo tipo la ONU o la OMC). Cuarto, porque contribuiría al fortalecimiento de la autonomía en la toma de decisiones en la región. Quinto, porque ayudaría a construir una imagen positiva para México ante un contexto interno adverso (lo que contribuiría a aumentar su capacidad de negociación internacional).

Si atendemos al estado actual de las cosas, no debe concluirse, a priori, que México carece de algún tipo de interés en América Latina. A pesar de su papel aún marginal ha logrado mantener su lugar en la región, explotando una estrategia diplomática comercial que, también, puede tener implicaciones políticas. No hay que olvidar que la Celac es un espacio de simple interlocución simbólica en donde los acuerdos no tienen carácter vinculante; pero esa misma cualidad, puede resultar en una herramienta eficaz de lobby en donde los mandatarios y ministros, así como los grupos de trabajo se encuentren frente a frente para discutir los temas de la agenda de trabajo.

La construcción de una cooperación política regional particular -que podría tener un escenario de actuación y expresión en el seno de la Celac- debería centrarse en desarrollar una coordinación basada en la noción de países likeminded como lo plantea Van Klaveren que resalta la preferencia por la formación de códigos de conducta y estructuras ideacionales que guíen los acuerdos (además legítimos ante las normas del derecho internacional), en lugar de erigir burocracias regionales que en su momento puedan limitar los intereses individuales de los Estados. Lo anterior, se puede ver beneficiado por el golpe de timón que se ha dado en la política regional y la transición hacia fuerzas políticas conservadoras o de derecha con una visión positiva ante el libre mercado y la profundización de la globalización; esto concuerda abiertamente con el proyecto de nación y el interés nacional que México persigue y profundiza desde los años 80 del siglo xx.

\section{CONCLUSIONES}

La diplomacia de cumbres, además de ser una característica predominante de las estrategias 
de cooperación regional en América Latina (no importa la filiación ideológica o los objetivos) es uno de los instrumentos de las políticas exteriores de los Estados para plantear expectativas conjuntas y buscar intereses comunes sin la necesidad de institucionalizar normas en un espacio geográfico y político particular. La diplomacia de cumbres son el resultado de una voluntad política, pero no una obligatoriedad internacional/regional.

La Celac, por sus características y objetivos principales, es un espacio para que, en su interior, se establezcan redes de liderazgos múltiples simultáneos y convergentes. En la formación de la Celac, en ningún momento se planteó la posibilidad de sustituir las funciones y el alcance de la OEA porque las premisas de su nacimiento eran distintas, a pesar de que una de las varias razones de su surgimiento fuera el reconocimiento de que el órgano panamericano tenía serias limitantes, en cuestiones de legitimidad, agilidad y efectividad en las acciones, que tenía para propiciar un verdadero diálogo y solucionar conflictos entre las partes.

Como campo de acción de la política exterior mexicana, la Celac aún no se ha desarrollado cabalmente debido a que no existe una estrategia concreta que guíe la ejecución de dicha política en su seno. Las oportunidades que hasta ahora la Comunidad representa no rebasan el hecho de ofrecer una mesa de diálogo, pero no supera las vicisitudes del contexto fragmentado y de inestabilidad política en algunos países, que también ha desembocado en un giro de sus políticas exteriores.

Hasta el momento México se ha contentado con ser un espectador de las cumbres de la
Celac, a pesar de haber sido, en un comienzo, uno de sus más activos impulsores. Hace falta que el país monitoree los resultados obtenidos en cada una de las cumbres, pudiendo estimar con ello la cantidad de recursos humanos y materiales que se requieren para la formulación de estrategias de trabajo en el seno de la Celac. Lo anterior, sería un elemento contundente para ampliar la representación y presencia de la política exterior mexicana en la construcción de proyectos e iniciativas que se realicen en América Latina.

La Celac, por su característica principal de ser un espacio informal de búsqueda de confluencias, puede redinamizar la política exterior de América Latina por medio del criterio likeminded, que en realidad no requiere del establecimiento de instituciones formales y no acarrea, por lo tanto, acuerdos vinculantes que vulneren la aplicación de políticas nacionales.

Sin embargo, la Comunidad no representa una prioridad tangible y a corto plazo dentro de las estrategias de política exterior en la administración de Peña Nieto que ha dado prioridad al aumento y profundización de los intercambios económicos y las zonas de libre comercio en detrimento de un fortalecimiento de los espacios de concertación política tendientes a crear un diálogo regional menos accidentado. Lo anterior, debilita la estrategia de política exterior en su conjunto porque no cuenta con contrapesos sólidos para hacer frente a un contexto externo más crítico y hostil, sobre todo en lo que se refiere a su relación con EE.UU.

En este sentido, creemos que los cambios en el contexto latinoamericano en relación al viraje hacia la derecha, que se observa en varios 
países, pueden ser positivos en cuanto hay una abierta identificación de proyectos e intereses que se relacionan con la profundización de la globalización y el libre comercio. Por lo tanto, la desconfianza que en otro tiempo se le tenía a México por su cercana relación con EE.uU. puede superarse (al menos provisionalmente) porque hay más países latinoamericanos buscando lo mismo que su par mexicano.

La Celac no es la panacea para que los problemas de América Latina se acaben de una vez y la desconfianza (sumada al desconocimiento) entre los países que la conforman desaparezca de una vez y para siempre. No obstante, más allá de los recursos retóricos e invariablemente vacíos que aluden a la unión latinoamericana, la Comunidad puede cumplir un rol importante de cabildeo y coordinación de opiniones para destrabar, impulsar o ampliar los temas más apremiantes de la agenda.

La política exterior de México debe combinar la noción que tiene de la diversificación de relaciones (que atiende más a objetivos económicos) con una en donde los lazos políticos también se multipliquen en atención al interés de convertirse en una potencia emergente y/o un jugador global. La discusión no debe centrarse en saber si la política exterior de México hacia América Latina es activa, pasiva, indiferente o pragmática, porque es todo eso al mismo tiempo y en diferentes grados. Lo que hay que entender es que la actuación debe matizarse en cada contexto teniendo detrás una estrategia de continuidad, para evitar que propuestas como la Celac lleguen a ser solo el logro efímero de un gobierno particular.

La realidad es que México necesita tener una presencia en la región, no de líder o de puente, pero sí de participante activo en la toma de decisiones. Si algo hizo bien el gobierno calderonista fue entender que México estaba quedando al margen de los cambios en la cooperación política regional, y de grandes e importantes construcciones regionales que ya establecían zonas de influencia alrededor de países que abiertamente buscan el liderazgo.

Finalmente, notamos que la utilización de la Celac como herramienta de la política exterior mexicana para acercarse a América Latina tendría pocas probabilidades de prosperar si se tiene en cuenta que la política exterior ha seguido una estrategia pragmática de cooperación a diferentes velocidades, que inserta a México en una posición diferenciada y no coordinada, que le impide participar en diálogos constructivos.

\section{REFERENCIAS}

Ayllón, B. y Emmerich, N. (2015). Las relaciones entre Celac y China: concertación regional y cooperación Sur-Sur. Revista Perspectivas do Desenvolvimento, 3 (04), 1-25.

Ayuso, A. (2015). Los dilemas existenciales de la Celac. Opinión América Latina (301), Centro de Estudios y Documentación Internacionales de Barcelona.

Bonilla S., A. y Álvarez E., I. (2013). Desafíos estratégicos del regionalismo contemporáneo: Celac e Iberoamérica, Flacso.

Calduch, R. (1993). Dinámicas de la sociedad internacional, Madrid: Centro de Estudios Ramón Aceres.

Cardoso, A. R. (2013). México ante el renovado espíritu integracionista en América Latina y el Caribe. Revista Mexicana de Politica Exterior (97), 133-165. 
Camhaji, E. y Valenzuela, G. (2015). México le apuesta al mundo, entrevista a Rosario Green. Foreign Affairs Latinoamérica. 1 (15), 88-93.

Constitución Política de los Estados Unidos Mexicanos (2017). Recuperado de: http://www.sct.gob.mx/ JURE/doc/cpeum.pdf

Costa Fernández, O. (2013). Introducción: el multilateralismo en crisis. En Revista CIDOB d'Afers Internacionals, (101), 7-25.

Del Arenal, C. (2007). Introducción a las relaciones internacionales, Madrid: Tecnos, 477.

De la Barra, X. and Dello Buono, R. A. (2012). From Alba to Celac toward another integration?, Nacla Report on the Americas 45:2, 32-36, DOI: 10.1080/10714839.2012.11722088

Franzoni, M. (2017). La política exterior de México en el gobierno de Peńa Nieto: Retos locales e internacionales. En Contextualizaciones Latinoamericanas (17), 1-9.

Gobierno de la República. (2013). Plan Nacional de Desarrollo 2013-2018. Recuperado de: http:// pnd.gob.mx/

González, G. (2001). Las estrategias de política exterior de México en la era de la globalización. Foro Internacional, 41, 4(166), 619-671.

González, G. y Pellicer, O. (Coords.) (2013). La politica exterior de México. Metas y obstáculos, México: ITAM, Siglo XXI.

Herrera S., D. (2011). La política exterior como pensamiento estratégico y la funcionalidad de las estrategias dentro de una concepción procesal. En Revista Electrónica Escenarios XXI, Año II, (10), http:/www.escenarios21.com/textos/2011/JulioAgosto/3148PolExtPensamientoHerrera.pdf

Hershberg, E.; Serbin, A. y Vigevani, T. (2014). La nueva dinámica hemisférica: desafíos y potencialidades. En Hershberg, E.; Serbin, A. \& Vigevani, T. (eds.). El hemisferio en transformación: Regiona- lismo, multilateralismo y políticas exteriores en un entorno cambiante, Buenos Aires: Cries-Cegre, 11-31.

Kegley, C. y Wittkopf, E. (1991). American Foreing Policy. Pattern and Process, Nueva York: St. Martin's Press.

Lafer, C. (2000). Dilemmas and challenges in Brazil's foreign policy. Estudos Avançados, 14(38), 63-71.

Lasagna, M. (1995). Las determinantes internas de la política exterior: un tema descuidado en la teoría de la política exterior. Estudios Internacionales, 28 (111), Recuperado de: http://www.jstor.org/ stable/41391524

Legler, T. (2010). Multilateralism and regional governance in the Americas. En focal (ed.). Latin America Multilateralism: New directions. Canada: focal. 12-17. Recuperado de http://www10.iadb.org/ intal/intalcdi/PE/2010/06396.pdf

Llenderrozas, E. (2013). Política exterior latinoamericana y la Comunidad de Estados Latinoamericanos y Caribeńos. En Bonilla, A. y Álvarez, I. (eds.). Desafíos estratégicos del regionalismo contemporáneo: Celac e Iberoamérica, San José: Flacso, 129-149.

Manaut, R. B. (2016). México: La trampa diplomática entre Estados Unidos y América Latina. Soft Power sin Hard Power. En Revista Pensamiento Propio (42), 79-106.

Méndez, R. (1970). Los principios del derecho de los tratados. Boletin Mexicano de Derecho Comparado, III (7), 83-108. DOI: http://dx.doi.org/10.22201/ iij.24484873e.1970.7M

Merino, M. (2013). Politicas públicas. Ensayo sobre la intervención del Estado en la solución de problemas públicos. México: CIDE.

Morgenthau, H. (1948), Politics among nations. The struggle for power and peace. New York: A. A. Knopf.

Muñoz, H. (1987). El estudio de las políticas exteriores latinoamericanas: temas y enfoques dominantes. 
En Estudios Internacionales, 80 (20). 406-434. DOI: $10.5354 / 0719-3769.2011 .15696$

Porcelli, E. (2013). Lo esencial es invisible a los ojos. El constructivismo en las relaciones internacionales. En Elsa Llenderrozas (coord.), Relaciones internacionales: teorias y debates, Argentina: Eudeba. 65-105.

Rojas Aravena, F. (coord.). (2011). Multilateralismo vs. Soberania: la construcción de la Comunidad de Estados Latinoamericanos y Caribeños, Buenos Aires: Teseo; Flacso.

Tomassini, L. (1991). La política internacional en un mundo postmoderno, Buenos Aires: Grupo Editor Latinoamericano.

Saltalamacchia, N. (2011). México y la CeLAC: recuperando la idea de América Latina. En Rojas Aravena, F. (coord.), Multilateralismo vs. Soberanía: la construcción de la Comunidad de Estados Latinoamericanos y Caribeños, Buenos Aires: Teseo, Flacso, 99-110.

Sanahuja, J. A. (2016). Regionalismo e integración en América Latina: de la fractura Atlántico-Pacífico a los retos de una globalización en crisis. En América Latina: de la bonanza a la crisis de la globalización, Revista Pensamiento Propio, 44 (21), julio-septiembre. 26-76.

Sanahuja, J. A. (2017). Enfoques diferenciados y marcos comunes en el regionalismo latinoamericano: alcance y perspectivas de Unasur y Celac. Revista Pensamiento Propio (39). 75-108.

Santa Cruz, A. (ed.) (2009). El constructivismo y las relaciones internacionales. México: Cide, 125-171.

Schiavon, J.; Spenser, D. y Vázquez, M. (eds.) (2006). En busca de una nación soberana. Relaciones internacionales de México, siglos XIX y XX, México: Cide, sRE.
Segovia, D. (2013). Latin America and the Caribbean: Between the OAS and Celac. European Review of Latin America and Caribbean Studies, (95), October, 97-107.

Singer, J. D. (1973). Sistema global, subsistemas y vinculaciones nacionales-internacionales. Tr. A. Bonnano. Buenos Aires: Nueva Visión.

Soriano, J. P. (2012). Dilma y México: altibajos de una relación indispensable para América Latina. En Revista СIDОВ d'Afers Internacionals, (97-98), 142.

Valencia, A. R. (2015). La Celac en la cúspide de los procesos de integración regional: más allá de un foro político-diplomático y más acá de una organización política internacional. En Contextualizaciones Latinoamericanas (10), 1-11.

Van Klaveren, A. (2012). América Latina en un nuevo mundo, Revista СIDOв d'Afers Internacionals, (100), 131-150.

Velázquez, F. R. (2007). Factores, bases y fundamentos en la politica exterior de México, México: Plaza y Valdés; Universidad del Mar.

Vitelli, M. (2014). Veinte años de constructivismo en relaciones internacionales. Del debate metateórico al desarrollo de investigaciones empíricas. Una perspectiva sin un marco de política exterior. Posdata, 19 (1), 129-162. Recuperado de: http://www.scielo.org.arg/scielo.php?pld=S1851$96012014000100005 \&$ script=sci_arttext

Wendt, A. (1999). Social Theory of International Politics. Cambridge: Cambridge University Press. 